30.P6

\title{
Retina-to-Retina Transplantation of Embryonic Donor Cells, Labelled with BrdU or Carrying a Genetic Marker
}

\author{
Robert Aramant and Magdalene Seiler \\ Eye Research Institute and Harvard Medical School, Boston, MA, USA
}

\section{INTRODUCTION}

Our experimental model is the transplantation of embryonic retina to injured adult host retina (Aramant et al. 1991, in: Retinal Degenerations, CRC Press, p. 275; Seiler et al. 1991, Neuro-opthalmology 11: 263). The immature neuroblastic donor cells differentiate into the different cell types and layers found in normal retina. Distinguishing graft from host cells is often difficult; therefore, it is necessary to find a reliable marker for the transplanted cells. If donor cells are incubated with a cytoplasmic label before transplantation, the label can diffuse out and be taken up by host cells when transplant cells degenerate. To overcome this problem, we have applied two strategies: transplantation of BrdU-labelled cells and of transgenic mouse cells, carrying the $E$. coli $\beta$ galactosidase gene.

\section{PRINCIPLES OF BrdU-LABEL}

Bromo-desoxy-uridine (BrdU) is incorporated into the DNA of cells undergoing mitosis within hours after injection. Cell nuclei are stained immunohistochemically with different intensities depending on the number of cell divisions after the BrdU-label.

\section{BrdU-LABELLED RETINAS AND TRANSPLANTS}

Timed-pregnant Long-Evans rats were injected with $40 \mathrm{mg} / \mathrm{kg} \mathrm{BrdU}$ at E16 and E17. Immunohistochemistry for BrdU was performed with HCl-pretreatment of the sections (Sieradzan \& Vrbová 1989, Neuroscience 31:
115). At embryonic day (=E) 18 , labelled cells were seen throughout the retina. At E21, labelled cells were found mostly in the outer neuroblastic layer, and occasionally in the ganglion cell layer. At postnatal day $(=P) 21$ (mature retina) labelled cells were seen mostly in the inner and outer retinal layers, with few labelled cells in the ganglion cell layer. BrdUlabelled retinal donor cells, transplanted at E21 to adult normal Long-Evans rats, could be distinctly identified immunohistochemically 9 weeks after transplantation. Some labelled transplant cells were found inside the unlabelled host retina, close to the graft.

\section{TRANSGENIC NSE lacZ MICE}

Transgenic NSE-lacZ mice (Dr. Sutcliffe, La Jolla, CA) contain the $E$. coli $\beta$-galactosidase gene, coupled to the neuron-specific enolase (NSE) promotor (Forss-Petter et al. 1990, Neuron 5: 187). In the retina of this mouse strain, the transgene is expressed in the ganglion cell layer, in part of the inner nuclear layer, the inner plexiform and outer plexiform layers. We have investigated the expression of the transgene by immunohistochemistry (Shimohama $e t$ al. 1989, Mol Brain Res 5: 271) and by histochemistry (Sanes et al. 1986, EMBO J 5: 3133).

\section{TRANSGENIC TRANSPLANTS TO NUDE RATS}

Transgenic mouse retinal donor cells have been transplanted to the retinas of immunodeficient "nude" rats. The donor age was E18. In the transplants (survival time 6 and 14 weeks), the transgene was not only expressed in a part of 
the inner retinal neurons, but also in photoreceptors, presumably cones (because cones are immunoreactive for NSE). When no apparent glial barriers were present between host and graft, $E$. coli $\beta$-galactosidase-immunoreactive transplant cells and few fibers could be seen inside the host retina, close to the graft. The cells could have been mixed with host tissue during transplantation. However, the presence of immunoreactive fibers in the host retina indicates outgrowth of donor cell processes.

\section{SUMMARY}

The two presented methods (BrdU-label and NSElacZ transgenic donor tissue) can reliably label neuronal donor tissue for transplantation without diffusion problems. However, both labelling methods do not label all donor cells. Therefore, unlabelled donor cells cannot be distinguished with certainty from host cells, but a labelled cell is unequivocally identified as a donor cell.

Supported by NIH grant EYO 8519. 

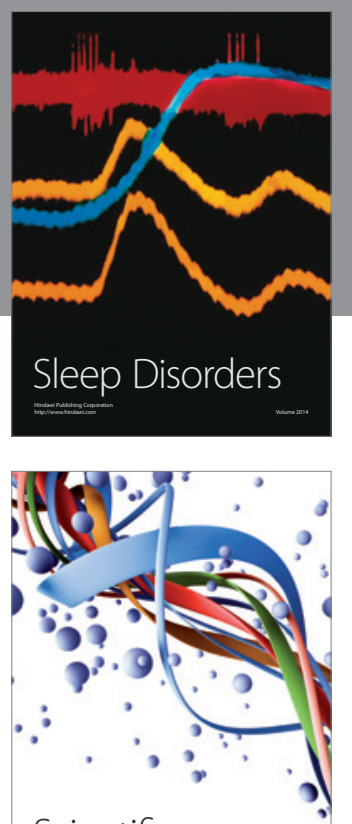

Scientifica
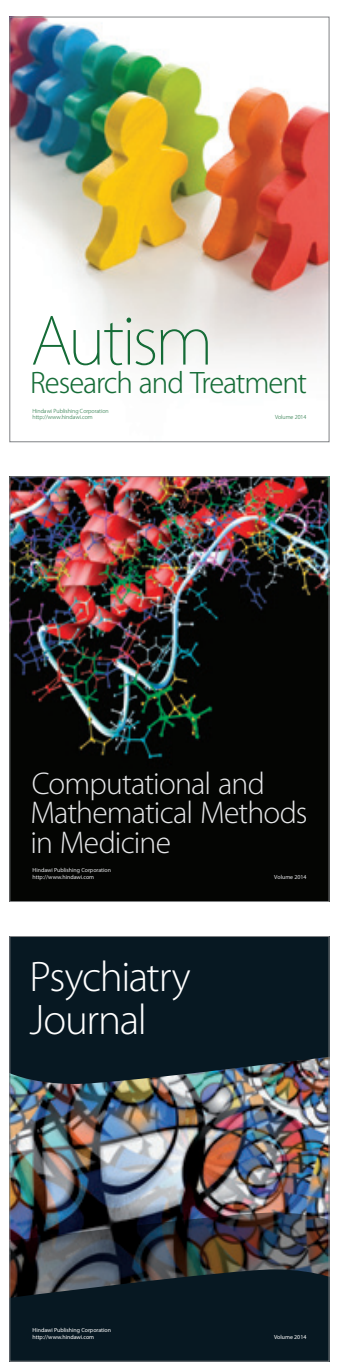
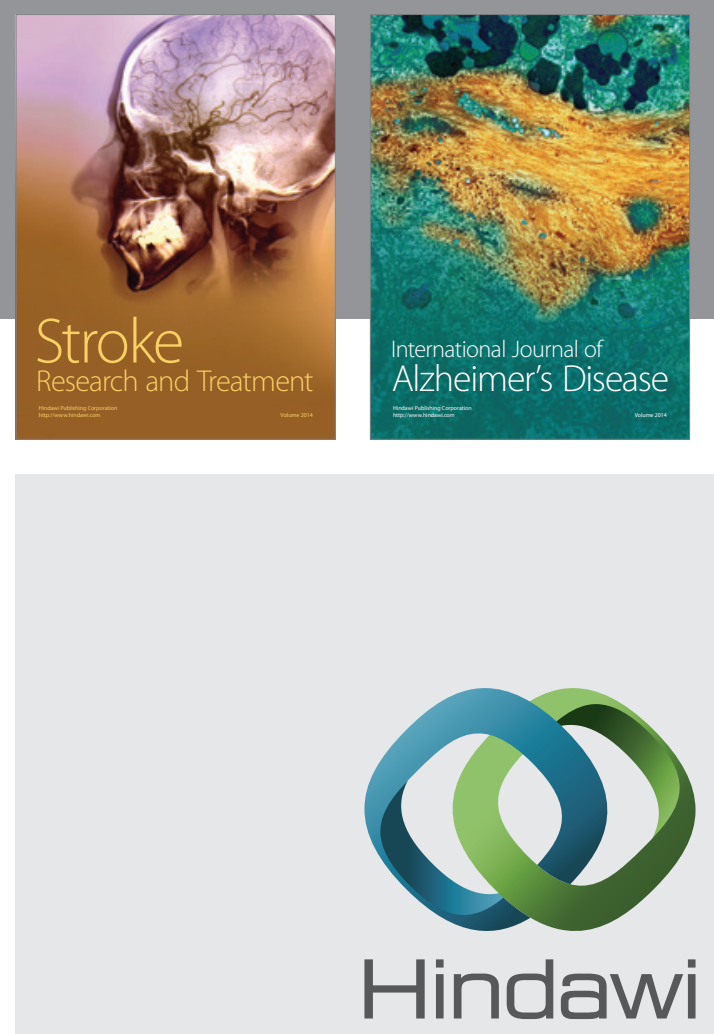

Submit your manuscripts at

http://www.hindawi.com
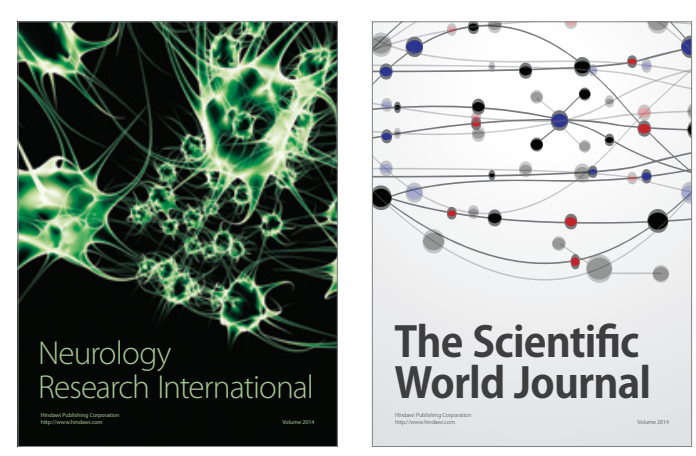

The Scientific World Journal

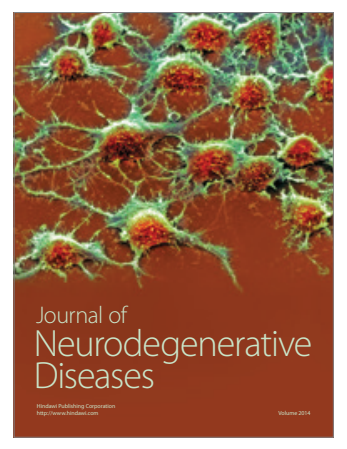

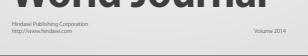

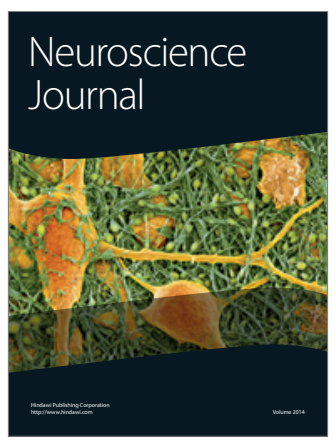

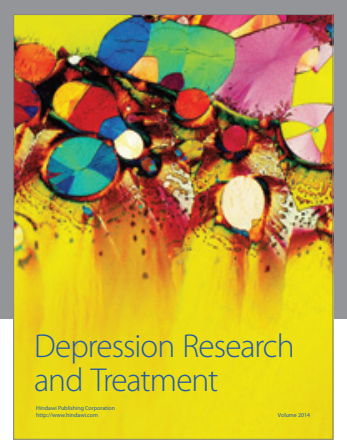
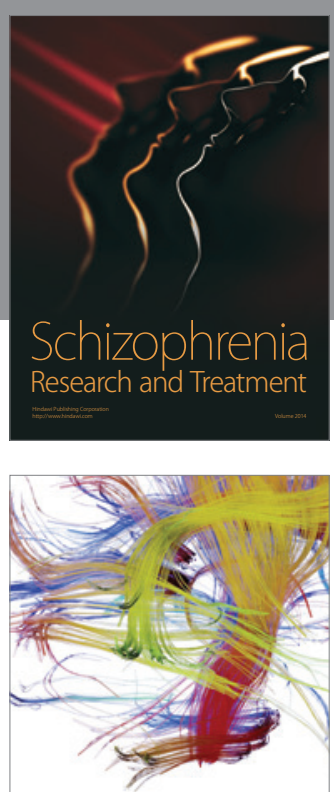

Brain Science

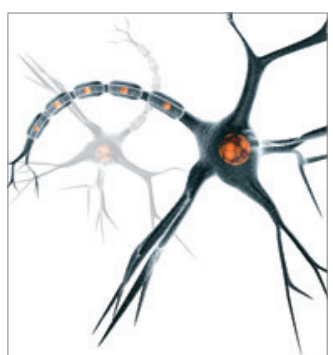

Neural Plasticity
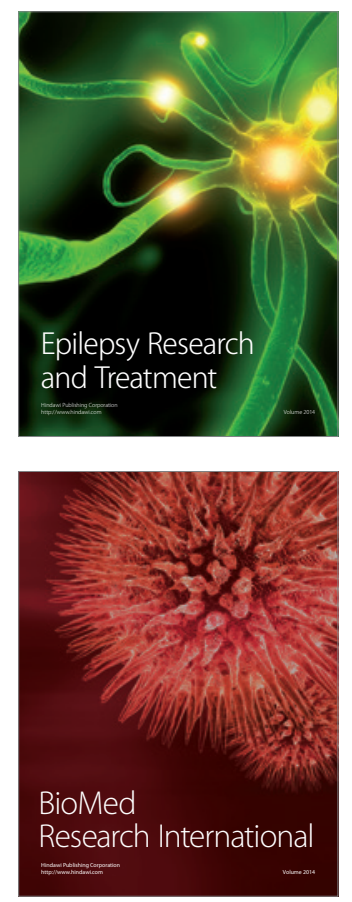

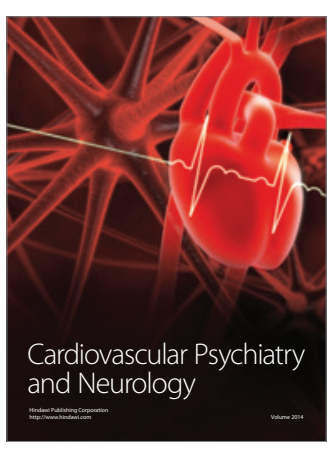

Parkinson's

Disease
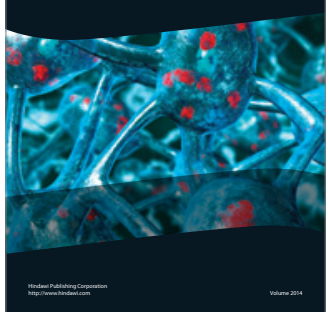